- RAM, REV. ADM. MACKENZIE, 16(6), Edição Especial • SÃO PAULO, SP • NOV./DEZ. 2015 • ISSN 1518-6776 (impresso) • ISSN 1678-6971 (on-line) • http://dx.doi.org/10.1590/1678-69712015/administracao.v16n6p126-158. Submissão: 5 abr. 2014. Aceitação: 14 jun. 2015. Sistema de avaliação: às cegas dupla (double blind review). UNIVERSIDADE PRESBITERIANA MACKENZIE. Silvio Popadiuk (Ed. e Ed. Seção), p. 126-158

\title{
NECESSIDADES DE TREINAMENTO: UMA PROPOSTA DE AVALIAÇÃO ESTRATÉGICA NO CONTEXTO DE EMPRESAS JUNIORES BRASILEIRAS
}

\section{ELZIANE BOUZADA DIAS CAMPOS}

Mestra em Psicologia Social e do Trabalho pelo Instituto de Psicologia da Universidade de Brasília (UnB). Doutoranda em Psicologia Social e do Trabalho do Instituto de Psicologia da Universidade de Brasília. Rua Randolfo Silva, 248/102, Mangabeiras, Sete Lagoas - MG - Brasil - CEP 35700-432

E-mail: elzibdc@gmail.com

\section{GARDÊNIA DA SILVA ABBAD}

Doutora em Psicologia Social e do Trabalho pelo Instituto de Psicologia da Universidade de Brasília (UnB). Professora associada 2 do Instituto de Psicologia da Universidade de Brasília. Campus Darcy Ribeiro, ICC Sul, Instituto de Psicologia. Laboratório de Avaliação de Sistemas Instrucionais, Asa Norte, Brasília - DF - Brasil - CEP 70910-900

E-mail: gardenia.abbad@gmail.com

\section{ANDRESSA GONZALEZ AZEVEDO PINHEIRO SOARES MACEDO}

Graduada em Psicologia pelo Instituto de Psicologia da Universidade de Brasília (UnB).

Analista de recursos humanos regional das Lojas Americanas. SQN 107 BI H, ap. 201, Asa Norte, Brasília - DF - Brasill - CEP 70743-080

E-mail: andressagonzalez62@gmail.com

\section{NATÁLIA PIMIENTA SILVA}

Graduada em Psicologia pelo Instituto de Psicologia da Universidade de Brasília (UnB). Técnica judiciária na área administrativa do Tribunal Superior do Trabalho (TST). Setor de Administração Federal Sul (Safs), Quadra 8, Lote 1, Bloco B, sala 526,

Asa Sul, Brasília - DF - Brasil - CEP 70070-600

E-mail: nataliapimentas@gmail.com

Este artigo pode ser copiado, distribuído, exibido, transmitido ou adaptado desde que citados, de forma clara e explícita, o nome da revista, a edição, o ano, e as páginas nas quais o artigo foi publicado originalmente, mas sem sugerir que a RAM endosse a reutilização do artigo. Esse termo de licenciamento deve ser explicitado para os casos de reutilização ou distribuição para terceiros. Não é permitido o uso para fins comerciais. 


\section{RESUMO}

A análise da literatura aponta ser necessário realizar pesquisas empíricas fundamentadas nas proposições e modelos teóricos de avaliação de necessidades de treinamento (ANT). Não há relatos de identificação de necessidades de treinamento no contexto de empresas juniores (EJs), organizações que contribuem para a formação profissional de alunos do ensino superior. Esta pesquisa teve como objetivos analisar as necessidades de treinamento de empresários juniores brasileiros e identificar os desafios e as mudanças enfrentados pelas EJs que podem gerar futuras demandas por treinamento. Foram realizados dois estudos. O estudo I identificou as necessidades de treinamento de uma amostra de empresários juniores e foi realizado em quatro etapas: I. concepção de um questionário de ANT com 43 itens associados a escalas de iI pontos para domínio e importância, 2. validação semântica, 3. aplicação em uma amostra de 447 empresários juniores de todo o país e 4. análise dos dados para identificação de necessidades de treinamento prioritárias. O estudo II identificou os desafios e as mudanças vivenciados pelas EJs que podem gerar futuras necessidades de treinamento para empresários juniores e envolveu as seguintes etapas: I. concepção de roteiro de entrevista semiestruturado, 2. entrevistas individuais com amostra de 2I profissionais e docentes, 3. entrevistas coletivas com amostra de 34 empresários juniores e 4. análise dos dados para descrição e categorização dos desafios e mudanças. Os achados do estudo I indicam que as necessidades de treinamento prioritárias referem-se a capacidades de gestão estratégica da EJ e de gerenciamento pessoal do tempo; e as de menor prioridade referem-se à comunicação efetiva e à capacidade de estabelecer relacionamentos cooperativos. Os resultados do estudo II descrevem desafios e mudanças diversos, mais bem especificados pela amostra de profissionais e docentes, que podem gerar futuras necessidades de treinamento. Discute-se a possibilidade de promover ações de treinamento estrategicamente elaboradas que impliquem o aprimoramento das atividades e dos projetos dos empresários juniores, e a oferta de produtos e serviços de qualidade superior. Contribui-se para o avanço de uma visão integrada entre análises diagnósticas e prognósticas de necessidades de treinamento, ainda que com limitada precisão. 


\section{PALAVRAS-CHAVE}

Necessidades de treinamento. Empresários juniores. Competências. Contexto. Desenvolvimento profissional.

\section{INTRODUÇÃO}

Este trabalho teve como objetivos avaliar as necessidades de treinamento de empresários juniores brasileiros e descrever os principais desafios e mudanças enfrentados na realização de atividades e projetos. Esta pesquisa é de natureza empírica e tem caráter exploratório.

Empresários juniores são alunos de graduação de instituições de ensino superior (IES) que são integrantes de empresas juniores (EJs). Constituída e gerenciada exclusivamente por esses alunos, uma EJ é uma associação civil, sem fins econômicos, que presta serviços referentes à(s) área(s) de formação do(s) curso(s) e desenvolve projetos para empresas, entidades e sociedade em geral (Brasil Júnior, 20II).

A Confederação Brasileira de Empresas Juniores, a Brasil Júnior (BJ), é a representante legal das EJs no país e responsável por divulgar e fomentar o Movimento das Empresas Juniores (MEJ). Atualmente, a BJ é formada por I4 federações, representando I3 Estados e o Distrito Federal (Brasil Júnior, 2009).

A BJ estimou a existência de aproximadamente I.I2o EJs localizadas no país, realizando em torno de 2.500 projetos por ano e contando com a participação de aproximadamente 27.800 empresários juniores (Brasil Júnior, 20I0). Se comparado ao ano de 2010 , o número de projetos realizados cresceu I3\%, e o somatório do faturamento anual das EJs, 7,8\%, o que corresponde a R\$ 8.652.407,92 (Brasil Júnior, 20I0, 2012).

Os objetivos de uma EJ incluem desenvolvimento técnico e acadêmico dos membros, desenvolvimento econômico e social da comunidade, fomento do empreendedorismo, contato dos alunos com o mercado de trabalho e o desenvolvimento pessoal e profissional deles (Brasil Júnior, 2008).

Quando os alunos ingressam em uma EJ, buscam resultados diversos: crescer profissionalmente (64\%); aplicar o conhecimento teórico aprendido (I5\%); complementar o currículo ( $9 \%)$; adquirir experiência para abrir o próprio negócio (4\%); ser agente de transformação do país (3\%); e aumentar a rede de relacionamentos (I\%) (Brasil Júnior, 20I2).

As EJs têm sido consideradas espaços de formação profissional em expansão no ensino superior de todo o país, promovendo impactos sociais e econômicos: 
sociais, ao integrar aluno e mercado de trabalho e ao fomentar o empreendedorismo; econômicos, pois integrantes atuam diretamente no mercado e atendem a demandas de nichos menos favorecidos por serviços de consultoria especializada a preços acessíveis.

Com base nesse entendimento, atualmente, está tramitando no Senado Federal o Projeto de Lei n. 437 (20I2) que tem o objetivo de regulamentar a criação e o funcionamento das EJs do país.

Apesar da avaliação positiva e do reconhecido papel das EJs de contribuir para a formação profissional de seus integrantes (Peres, Carvalho, \& Hashimoto, 2004; Moretto, Junkes, Rosauro, \& Benko, 2004; Matos, I997), alguns aspectos limitam esse impacto: não há medidas do nível de domínio dos empresários juniores quanto às competências qualificadoras de seu desempenho excelente e não se têm descritos os principais desafios e mudanças enfrentados pelas EJs que podem gerar necessidades de aprendizagem de novas competências. Diante desses aspectos, torna-se um limitador a elaboração de ações educacionais sistemáticas para o desenvolvimento profissional de empresários juniores.

Este trabalho pretendeu contribuir na superação dessa limitação ao I. avaliar as necessidades de treinamento de empresários juniores brasileiros e 2. descrever os principais desafios e mudanças enfrentados pelas EJs que podem pressionar para novas necessidades de treinamento.

Uma avaliação de necessidades de treinamento (ANT) é um processo que conjuga investigação e análise para a produção de insumos que embasem o desenvolvimento de competências no trabalho. O objetivo de uma ANT é identificar necessidades de treinamento expressas por lacunas de competências que impedem a caracterização de um desempenho no trabalho como excelente (Abbad, Coelho, Freitas, \& Pilati, 2006).

Competências são mobilizadas pelos indivíduos para alcançar determinado propósito no trabalho e constituem-se como combinações de conhecimentos, habilidades e atitudes (Abbad \& Borges-Andrade, 2004). Conhecimentos são definidos como um corpo organizado de informações de natureza técnica ou administrativa; habilidades referem-se à capacidade de desempenhar operações de trabalho com facilidade e precisão, incluindo comportamentos motores ou verbais; e atitudes são predisposições ou sentimentos favoráveis ou desfavoráveis em relação a um objeto, pessoa, fato ou sobre a organização (Magalhães \& Borges-Andrade, 200I).

Nas organizações, há a expectativa de que os indivíduos tenham as competências necessárias para realizar as atribuições de forma eficaz. Fala-se em necessidades de treinamento quando há discrepâncias entre "o que é" e "o que deveria ser" ou entre o nível atual de competências manifestas pelo indivíduo no desempenho e o nível que a organização espera dele (Borges-Andrade \& Lima, I983). 
Na descrição das necessidades de treinamento, do que treinar, a ANT identifica onde, quando e quem treinar. Dessa maneira, a ANT é responsável por fornecer subsídios para as demais etapas do treinamento e facilitar o alcance dos objetivos organizacionais. Apesar desse papel estratégico, a ANT tem sido recorrentemente negligenciada e é pouco sistemática em ambientes organizacionais (Abbad, 2009).

A análise da literatura sobre ANT revela que a evolução da área caminhou a passos lentos, com maior impulso nos últimos anos, mas sua produção ainda é restrita e carece de estudos empíricos (Ferreira, 2009). Os modelos teóricos que avançam na compreensão da ANT também indicam a necessidade de considerar uma visão prospectiva voltada para demandas emergentes, que gerarão necessidades de aprendizagem de novas competências (Abbad, 2009).

Considerando essas indicações, o presente trabalho apresenta um estudo empírico no contexto de EJ, contexto raramente estudado, e se propõe a contribuir no avanço da compreensão da ANT ao descrever necessidades de treinamento como competências que direcionem objetivos de aprendizagem e fundamentem um processo diagnóstico e prognóstico ou atual e prospectivo. Ressalta-se que, neste trabalho, as competências dos empresários juniores referem-se àquelas consideradas comuns a todo empresário júnior que almeja um desempenho de excelência, independentemente da área de atuação da EJ ou do cargo ocupado.

Esta pesquisa pretende contribuir para o avanço da área de ANT ao testar um modelo teórico por meio de um estudo empírico em um contexto pouco estudado e propõe a integração entre necessidades de treinamento atuais e emergentes para viabilizar a elaboração estratégica de ações educacionais. Este trabalho também pretende especificar parâmetros claros para a formulação de um programa de desenvolvimento nacional para empresários juniores brasileiros e fornecer subsídios para o fortalecimento de EJs, de modo a ofertar experiências de formação profissional mais efetivas.

\section{REFERENCIAL TEÓRICO}

As ações de treinamento, desenvolvimento e educação (TD\&E) são consideradas sistemas instrucionais compostos por três subsistemas interdependentes que se retroalimentam e interagem com o contexto organizacional (Borges-Andrade, 2006). A ANT é o primeiro desses subsistemas, definido como um processo que conjuga investigação e análise para a produção de insumos que embasem o desenvolvimento de competências no trabalho. 
O objetivo de uma ANT é identificar necessidades de treinamento expressas por lacunas de competências que impedem a caracterização de um desempenho no trabalho como excelente (Abbad, Freitas, \& Pilati, 2006) nos mais diversos contextos de atuação (Carlisle, Bhanugopan, \& Fish, 2oıı; Trudeau, Ainscough, Trant, Starker, \& Cousineau, 20ıо; Ajjawi, Thistlethwaite, Aslani, \& Cooling, 20ıо; Akhtar-Danesh et al., 2010; Ateudjieu et al., 20Iо; Cofré et al., 2010).

Nesta pesquisa, as necessidades de treinamento são descritas como objetivos instrucionais, ou seja, como descrições claras e precisas das competências que se deseja observar no comportamento do aprendiz após a realização do treinamento, quando as necessidades dele são sanadas e irão caracterizar o desempenho como excelente (Abbad, Zerbini, Carvalho, \& Meneses, 2006). Essa escolha metodológica indica um avanço por permitir a integração de todos os subsistemas instrucionais, fundamentando o planejamento, a execução e a avaliação de ações educacionais.

Quando se redige um objetivo instrucional, utilizam-se um verbo para indicar a ação do indivíduo treinado, um objeto no qual essa ação recai, as condições na qual essa ação ocorre e um critério capaz de caracterizar a ação ou o comportamento como um desempenho excelente ou indicar um padrão de qualidade satisfatório (Mager, I977; Meneses, Zerbini, \& Abbad, 20I0).

Além disso, com as necessidades de treinamento descritas na forma de objetivos instrucionais, pode-se fazer uso de taxonomias de aprendizagem como as elaboradas por Bloom, Krathwoh e Masia (I973) e Bloom, Engelhart, Furst, Hill e Krathwohl (I976) para classificar e hierarquizar as competências humanas. Isso possibilita a identificação das expectativas e padrões organizacionais de excelência, e a elaboração de planos instrucionais compatíveis com a natureza e o grau de complexidade dessas competências (Abbad, Coelho et al., 2006).

O modelo teórico de ANT adotado nesta pesquisa é o de Abbad e Mourão (20I2). A escolha por esse modelo de pesquisa deveu-se à convergência de suas proposições com a análise crítica da literatura de ANT (Aguinis \& Kraiger, 2009; Abbad, 2009; Meneses et al., 20I0) e dos modelos que avançaram na sua compreensão (Iqbal \& Khan, 2OII).

As partes constituintes desse modelo estão representadas na Figura I e correspondem aos seguintes fatores: I. ambiente externo: referente à sociedade, à política, aos stakeholders, entre outros; 2 . ambiente organizacional: referente à estrutura organizacional como um todo; 3. macroprocessos: processos produtivos que extrapolam a estrutura da organização; 4 . grupos ou equipes: conjunto específico de profissionais ou de unidades de eixo comum; e 5. indivíduos e suas características demográficas e profissiográficas. 
Figura I

\section{MODELO TEÓRICO DE ANT PROPOSTO \\ POR ABBAD E MOURÃO (20I2)}

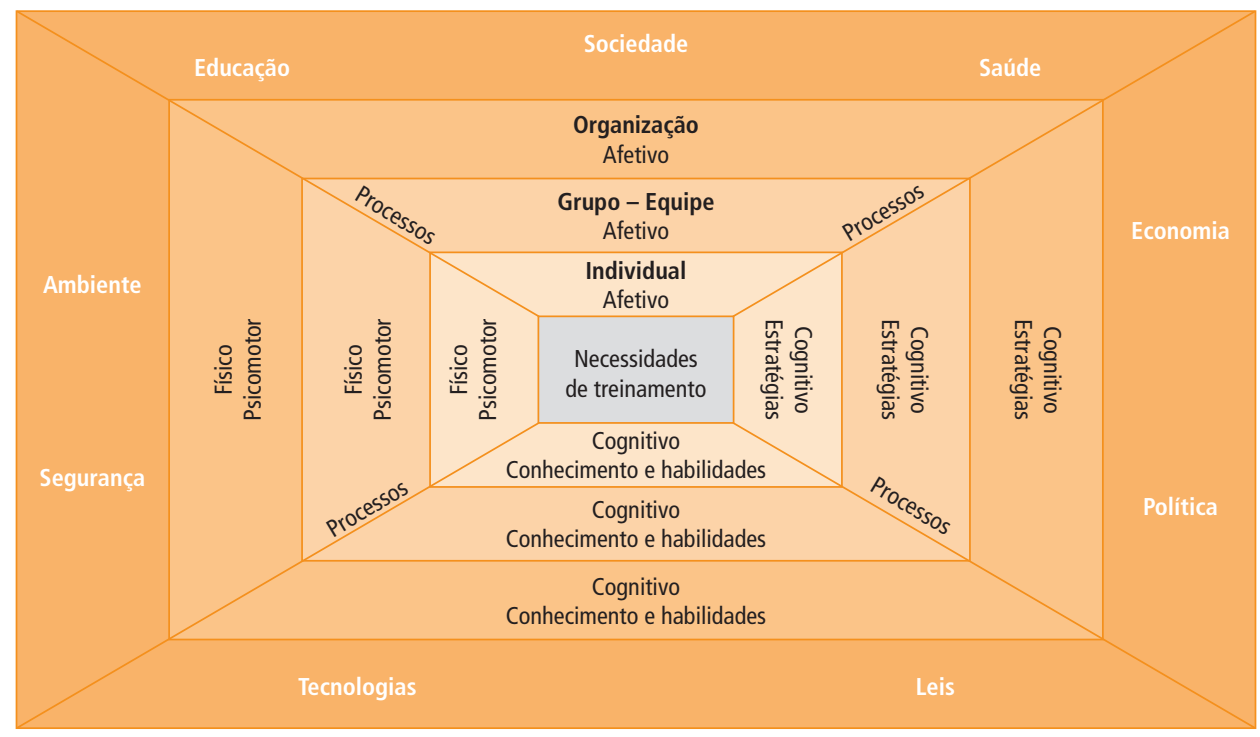

Fonte: Abbad e Mourão (20I2).

Esse modelo supera os modelos tradicionais de ANT - modelos organização-tarefa-pessoa de McGehee \& Thayer (I96I) e de análise de desempenho individual de Mager \& Pipe (I979) - ao ampliar os elementos que devem ser analisados antes da identificação das lacunas de competências. Outros avanços desse modelo se referem à inserção da prerrogativa de Goldstein (I980) sobre a relevância de se utilizar das proposições da teoria instrucional e das taxonomias de resultados de aprendizagem para descrever necessidades de treinamento como objetivos instrucionais, e de Latham (ig88) no que se refere ao fato de a análise individual ser feita com análises demográficas, no intuito de identificar necessidades específicas relacionadas a características como gênero, idade, posição hierárquica e nível de escolaridade.

O modelo também atende às indicações de Tannenbaum e Yukl (I992) e Taylor, O’Driscoll e Binning (I998) sobre a importância da necessária ligação de ações educacionais com a estratégia organizacional, bem como a preocupação com as necessidades futuras de treinamento geradas a partir de demandas emergentes no trabalho quando se consideram variáveis contextuais influentes.

O modelo adotado considera as proposições do modelo multinível de Ostroff e Ford (1989), segundo as quais as necessidades de treinamento de diferentes níveis 
de análise são singulares, portanto não podem ser a simples soma de necessidades de níveis inferiores nem dimensionar o nível de entrega do treinamento a indivíduos, grupos e equipes ou organização. Essa referência à qualidade multidimensional das necessidades de treinamento foi enfatizada também por Kozlowski, Brown, Weissbein, Cannon-Bowers e Salas (2000), Aguinis e Kraiger (2009) e Ferreira (2009).

Segundo o modelo de Abbad e Mourão (2012), a origem das necessidades de treinamento estaria vinculada às pressões de variáveis contextuais internas e externas da organização em seus diversos níveis, tanto de nível meso (como quando se adota uma nova tecnologia ou sistema em um projeto de uma EJ) quanto de nível macro (como oscilações no mercado de trabalho, diversificação da demanda de clientes das EJs etc.).

Essa indicação converge para a constatação do impacto de variáveis contextuais em influenciar a manifestação de competências, sugerindo que a ANT passe a ser tratada em caráter diagnóstico e preventivo, referindo-se à identificação de necessidades atuais que precisam ser sanadas e também de necessidades futuras que emergirão a partir de pressões exercidas pelas mudanças e pelos desafios contextuais (Abbad, Coelho et al., 2006; Freitas \& Brandão, 2006; Le Boterf, 2003).

Por fim, nesta pesquisa, optou-se por operacionalizar a ANT com base nas escalas e no cálculo propostos no modelo de análise do papel ocupacional de Borges-Andrade e Lima (I983). A escolha desse método de operacionalização deveu-se a pesquisas anteriores (Menezes, Rivera, \& Borges-Andrade, I988; Borges-Andrade, Lima, Soares, \& Paula, I989; Magalhães \& Borges-Andrade, 200I; Brandão, Guimarães, \& Borges-Andrade, 2002; Castro \& Borges-Andrade, 2004; Lima, Castro, \& Machado, 2004; Ferreira, Abbad, Pagotto, \& Meneses, 2009; Hoffman-Câmara, Abbad, Meneses, \& Ferreira, 20I0) que se mostraram exitosas ao utilizarem esse método e variações ou algumas de suas prerrogativas metodológicas para identificar necessidades de treinamento.

Borges-Andrade e Lima (I983) propuseram que a mensuração de necessidade de treinamento fosse realizada a partir de análises combinadas entre a importância e o domínio de competências para estabelecer prioridades de treinamento. Originalmente, as competências seriam dispostas como itens associados a duas escalas do tipo Likert: uma de domínio e outra de importância. As pessoas deveriam realizar uma autoavaliação da importância e do domínio de cada um dos itens, usando essas escalas dispostas em um intervalo de valor de o a 3. Na proposição desses autores, a importância deve ser combinada com a discrepância entre o domínio atual e o domínio ideal (o ponto extremo mais positivo da escala de domínio utilizada). Em termos operacionais, a necessidade $(\mathrm{N})$ seria definida como o produto dos julgamentos de importância (I) pelo inverso dos julgamentos de domínio (D), ou seja, $\mathrm{N}$ = I(3-D). 
Necessidades de treinamento seriam então identificadas nos itens com baixo domínio e alta importância. Para calcular o escore geral de prioridades por item, utiliza-se a equação IPG $=\sum[\mathrm{I}(3-\mathrm{D})] / \mathrm{n}$, em que IPG é o índice de prioridade geral de uma competência numa escala de o a 3; $I$, a importância do atributo julgado pelo respondente na escala; $D$, o domínio da competência julgada pelos respondentes na escala; e $n$, o número de respondentes. Com base nesse valor e no estabelecimento de um ponto de corte, é possível definir uma listagem dos atributos a serem treinados prioritariamente.

\section{PROCEDIMENTO METOdOLÓGICO}

Esta pesquisa foi dividida em dois estudos. O estudo I teve o objetivo de avaliar as necessidades de treinamento de empresários juniores brasileiros. O estudo II teve o objetivo de descrever os principais desafios e mudanças enfrentados pelas EJs que podem gerar futuras necessidades de treinamento para empresários juniores brasileiros.

\subsection{ESTUDO I}

O estudo I foi realizado em quatro etapas: I. concepção de um questionário de ANT; 2. validação semântica do questionário; 3. aplicação do questionário; e 4. análise dos dados, incluindo descrição dos dados e operacionalização da ANT por meio do cálculo do IPG.

\subsubsection{Participantes}

Participaram da pesquisa 447 estudantes universitários integrantes de EJs: $46,1 \%$ homens; $76,5 \%$ pertencentes à faixa etária entre i9 e 22 anos; a maioria (57,I\%) vinculada a cursos de graduação das áreas de humanas; residentes em grande parte no Sudeste (I5,8\%) e Centro-Oeste do país (I5,I\%); e membros efetivos e que ocupam cargos de direção na EJ (57,2\%).

\subsubsection{Instrumento}

Optou-se pela elaboração de um questionário em formato on-line, de modo a possibilitar a aplicação da pesquisa a empresários juniores de todo o país. Nesse questionário, as competências foram dispostas aleatoriamente, e os respondentes deveriam avaliar cada uma com base em duas escalas: uma de domínio e outra de importância. Ao contrário de Borges-Andrade e Lima (I983), optou-se 
por uma escala de iı pontos, variando de $\mathrm{o}$ a Io, de forma a oferecer maior liberdade aos respondentes para expressar as opiniões. Essas escalas também possuíam âncoras de significados opostos somente em seus extremos, sem âncoras nos pontos intermediários.

Após lerem atentamente cada competência, aos respondentes era solicitado que ema avaliassem nas escalas de domínio - "O quanto você considera que domina essa competência hoje?”, em que o correspondia a não domino essa competência, e Io, a domino totalmente essa competência - e de importância - "O quanto você considera essa competência importante para o sucesso da sua EJ?”, em que o correspondia a sem importância para o sucesso da EJ, e Io, a extremamente importante para o sucesso da EJ.

\subsubsection{Procedimentos de coleta de dados}

Para que se pudesse elaborar o instrumento de ANT, era necessário ter identificadas as competências dos empresários juniores. O trabalho de Campos (20I2) apresentou a descrição de 67 competências genéricas de empresários juniores, requeridas por qualquer empresário júnior, independentemente da área de atuação de sua EJ e do cargo ocupado.

Essas competências foram descritas por meio de análise documental e entrevistas coletivas com 34 empresários juniores de I2 cursos de graduação da Universidade de Brasília (UnB), ocupantes de cargos e de tempo variados de atuação na EJ. Essas competências também passaram por processo de validação, em que nove juízes avaliaram a pertinência prática, a clareza da linguagem e a classificação das competências em suas categorias temáticas.

Todas as 43 competências foram dispostas como itens do questionário. Mas, antes de aplicado, o instrumento de pesquisa precisou ser submetido à validação semântica, de forma a garantir sua compreensão por todos os futuros respondentes (Pasquali, I998). Especificamente, era necessário se certificar quanto à compreensão das escalas e das avaliações que teriam que ser realizadas. Além da compreensão desses aspectos, intencionava-se a identificação de eventuais falhas ou erros de disposição do questionário, discordâncias quanto ao preenchimento e possíveis ambiguidades. Participaram dessa etapa quatro empresários juniores de três diferentes cursos, cargos e EJs da UnB.

Em um encontro presencial, o questionário foi apresentado e preenchido pelos participantes. Ao término, solicitou-se aos empresários juniores que descrevessem como procederam, e, assim, foi confirmada a ausência de incompreensões ou erros nas instruções e na formatação do questionário.

Com a validação semântica finalizada, seguiu-se com a divulgação do link de acesso ao questionário nas redes sociais e o envio aos e-mails dos empresários 
juniores cadastrados na base de comunicação externa da BJ, sem a identificação dos respondentes e sem qualquer tipo de desvantagem para aqueles que não responderam ou desistiram sem completar todas as suas respostas.

Para a composição do banco de dados, foram considerados 447 participantes cujos missings de resposta aos itens não passavam dos $5 \%$. Com base nas respostas do questionário referente ao nível de domínio das competências, foi possível chegar a uma solução fatorial satisfatória que reduziu o número de competências para um total de 43 agrupadas em quatro fatores denominados: gestão estratégica da EJ, comunicação efetiva, desenvolvimento pessoal e relacionamento cooperativo.

A partir da solução fatorial encontrada e com a redução no número de competências em 43, realizaram-se análises descritivas das respostas às escalas utilizadas e o cálculo adaptado do IPG de necessidades de treinamento para cada competência.

\subsection{ESTUDO II}

O estudo II teve o objetivo de descrever os principais desafios e mudanças vivenciados pelas EJs que podem gerar futuras necessidades de treinamento para empresários juniores na realização de atividades e projetos. Esse estudo pretende ampliar os resultados do estudo I ao permitir uma análise dos fatores contextuais emergentes que podem pressionar para o aprendizado de novas competências.

Esse estudo também compara avaliações de empresários juniores e de profissionais pós-juniores e docentes orientadores de empresários juniores quanto à sua percepção de desafios e mudanças. A opção por incluir a perspectiva de profissionais e docentes decorreu do julgamento de que esses participantes teriam uma visão mais ampla sobre o contexto no qual as EJs se inserem e poderiam fornecer respostas mais abrangentes e críticas referentes aos principais desafios e mudanças enfrentados por empresários juniores.

Esse estudo foi realizado em quatro etapas: I. concepção de um roteiro de entrevista semiestruturado; 2. realização de entrevistas individuais com profissionais e docentes; 3. realização de entrevistas coletivas com empresários juniores; e 4. análise dos dados para descrição e categorização dos desafios e mudanças.

\subsubsection{Participantes}

A amostra de profissionais não juniores foi constituída de 2I participantes, sendo I3 pós-juniores (profissionais graduados que participaram de uma EJs), cinco docentes de IES orientadores de empresários juniores e três profissionais 
que trabalharam diretamente com o fomento e apoio a EJs no programa Pró-Júnior do Centro de Apoio ao Desenvolvimento Tecnológico da Universidade de Brasília (CDT/UnB). A amostra foi escolhida por conveniência e de modo a fornecer maior variabilidade de respostas.

Entre os 2I participantes, I3 eram homens, e oito, mulheres. Exceto por um participante (professor), os demais eram relacionados à EJ do Distrito Federal. Entre os profissionais pós-juniores, dois integraram EJs do curso de Direito, seis de Administração, um de Comunicação Social e quatro de Psicologia. Também haviam ocupado diferentes cargos e participado por períodos variados em suas EJs. Quanto aos professores, dois orientaram trabalhos de EJs da Administração, um de EJs da Administração e Comunicação Social e dois da Psicologia. Entre os profissionais que trabalhavam no apoio às EJs, um também já havia sido integrante de uma EJ de Psicologia.

Por sua vez, a amostra de empresários juniores foi constituída de 34 empresários juniores de 12 diferentes cursos de graduação da UnB (das áreas de humanas, exatas e biológicas), com idades entre I 8 e 25 anos, $26,47 \%$ mulheres, ocupantes de distintos cargos e de tempo médio de atuação na EJ de i 8,38 meses.

\subsubsection{Instrumento}

Para a realização das entrevistas tanto individuais quanto coletivas, foi elaborado um roteiro semiestruturado contendo perguntas para a identificação do perfil do participante e o questionamento: "Quais são os desafios e as mudanças que as EJs enfrentarão nos próximos anos?”.

\subsubsection{Procedimentos de coleta de dados}

As entrevistas individuais com profissionais não juniores foram realizadas presencialmente, sempre por dois pesquisadores: um responsável por conduzir a entrevista e o outro por realizar o registro simultâneo das respostas, de modo a facilitar a transcrição. Todas as entrevistas foram gravadas com autorização dos entrevistados.

A transcrição das entrevistas foi parcial, incluindo somente o registro de partes dos relatos considerados essenciais para realizar a análise de conteúdo. Para análise das respostas, utilizou-se uma variação do método proposto por Bardin (2002), em que foram realizadas análises das similaridades e diferenças entre as verbalizações, unindo-as em núcleos de sentido comum e elaborando termos descritores de seu significado geral, além da indicação da contagem das verbalizações dos entrevistados. 
Nas entrevistas coletivas, os empresários juniores foram primeiramente convidados a responder ao questionamento de maneira individual, seguido de compartilhamento e debate de suas respostas: concordâncias, discordâncias e especificidades de cada EJ. Realizaram-se seis entrevistas no total. Cada uma delas contou com a presença de um facilitador para sua condução e dois observadores para registrar o que foi debatido pelos participantes. Todos foram informados do caráter voluntário da participação, que seria mantido sigilo dos nomes e que os dados obtidos seriam tratados de forma agrupada.

Para a análise dos dados, adotou-se procedimento semelhante ao definido para as entrevistas individuais com profissionais e docentes, tendo sido consideradas tanto as respostas individuais quanto as verbalizações oriundas dos debates.

\section{RESULTAdos e ANÁLISES}

\subsection{ESTUDO I}

O estudo I teve o objetivo de avaliar as necessidades de treinamento de empresários juniores brasileiros. Para facilitar a visualização do padrão de distribuição das respostas aos itens de ANT, os pontos das escalas de domínio e importância foram agrupados em intervalos, e calculou-se a porcentagem de respostas aos itens para cada um desses intervalos. O primeiro intervalo englobava os pontos o, I, 2 e 3 das escalas, correspondendo a baixa importância e baixo domínio; o segundo intervalo englobava os pontos 4,5 e 6 das escalas, correspondendo a média importância e médio domínio; e o terceiro intervalo englobava os pontos 7, 8, 9 e io das escalas, correspondendo a alta importância e alto domínio.

As escalas de importância e domínio utilizadas nesta pesquisa para a operacionalização da ANT foram adaptadas, variando de o a ıo, o que alterou o cálculo do IPG que passou a utilizar a equação IPG $=\sum$ [I (Io-D)]/447. Também foi alterado o ponto de corte para diferenciar necessidades de treinamento prioritárias em futuras ações instrucionais.

No estudo de Borges-Andrade e Lima (1983), ao escolherem o ponto de corte 3 , os autores argumentam que tal escolha foi orientada pela matriz dos possíveis valores de prioridade resultante da combinação dos escores das escalas de domínio e importância, o que inclui possibilidades de escores de importância total combinados a escores de domínio quase total e de escores de sem domínio combinados a escores de pouca importância.

Nesta pesquisa, a escala de prioridades gerada pelo cálculo do IPG varia de $\circ$ a Ioo. O ponto de corte selecionado foi 25 , que inclui ao menos os pontos 
médios (5) das escalas de domínio e importância; importância 9 e ıo/domínio máximo 7; importância 7 e 8/domínio máximo 6; importância 5 e 6/domínio máximo 5; importância 4/domínio máximo 3; e importância 3/domínio o ou I.

A Tabela I traz os itens dispostos por fator com as distribuições das respostas nos intervalos de baixo, médio e alto domínio e importância.

TABELA I

DISTRIBUIÇÕES DAS RESPOSTAS NOS INTERVALOS DE BAIXO, MÉDIO E ALTO DOMÍNIO E IMPORTÂNCIA PARA AMOSTRA DE 447 PARTICIPANTES

\begin{tabular}{|c|c|c|c|c|c|c|c|}
\hline \multirow{3}{*}{ (1) } & \multirow{3}{*}{ ITEM } & \multicolumn{6}{|c|}{ DISTRIBUIÇÃO DAS RESPOSTAS (\%) } \\
\hline & & \multicolumn{3}{|c|}{ DOMÍNIO } & \multicolumn{3}{|c|}{ IMPORTÂNCIA } \\
\hline & & BAIXO & MÉDIO & ALTO & BAIXA & MÉDIA & ALTA \\
\hline \multirow{10}{*}{ 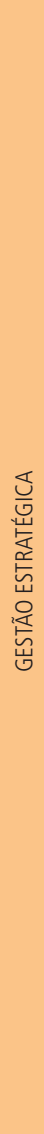 } & $\begin{array}{l}\text { 17. Identifico ameaças à comercialização de produtos } \\
\text { e serviços da EJ, considerando as características do mercado. }\end{array}$ & 12,1 & 36,2 & 51,7 & 0,2 & 4,7 & 95,1 \\
\hline & $\begin{array}{l}\text { 22. Proponho ações para expansão e desenvolvimento conjunto } \\
\text { da EJ e do MEJ (BJ, federações ou núcleos de EJ), de acordo } \\
\text { com diretrizes e estratégias de ambos. }\end{array}$ & 12,1 & 37,1 & 50,8 & 0,2 & 4,0 & 95,7 \\
\hline & $\begin{array}{l}\text { 42. Relaciono os principais processos do planejamento } \\
\text { estratégico, descrevendo seus componentes (objetivos, } \\
\text { indicadores, planos de ação etc.). }\end{array}$ & 6,5 & 24,2 & 69,4 & 0 & 3,4 & 96,6 \\
\hline & $\begin{array}{l}\text { 9. Busco parcerias e fontes de recursos (financeiros, } \\
\text { materiais e tecnológicos) para a EJ baseadas nos objetivos } \\
\text { organizacionais. }\end{array}$ & 8,7 & 30,6 & 60,6 & 0,2 & 4,0 & 95,7 \\
\hline & $\begin{array}{l}\text { 16. Capto projetos para a EJ, equilibrando a margem de lucro } \\
\text { e as possibilidades de aprendizagem dos membros. }\end{array}$ & 8,7 & 30,6 & 60,6 & 0,4 & 3,6 & 96,0 \\
\hline & $\begin{array}{l}\text { 25. Acompanho o alcance de metas que estão sob minha } \\
\text { responsabilidade com base em indicadores de resultados } \\
\text { do plano estratégico da EJ. }\end{array}$ & 3,1 & 19,0 & 77,9 & 0,2 & 1,6 & 98,2 \\
\hline & $\begin{array}{l}\text { 41. Descrevo os principais processos de gestão de cada área } \\
\text { ou diretoria da EJ, identificando suas interações. }\end{array}$ & 3,8 & 21,3 & 74,9 & 0 & 3,8 & 96,2 \\
\hline & $\begin{array}{l}\text { 26. Aprimoro produtos e serviços oferecidos pela EJ, } \\
\text { considerando as tendências do seu mercado de atuação. }\end{array}$ & 6,0 & 32,7 & 61,3 & 0 & 3,1 & 96,9 \\
\hline & $\begin{array}{l}\text { 30. Ao identificar necessidades do curso que possam ser supridas } \\
\text { com o auxílio da EJ, proponho ações que beneficiem } \\
\text { a empresa, professores e alunos. }\end{array}$ & 6,0 & 33,1 & 60,9 & 0,4 & 4,5 & 95,1 \\
\hline & 40. Participo ativamente de eventos promovidos pela EJ. & 4,0 & 13,0 & 83,0 & 0 & 4,0 & 96,0 \\
\hline
\end{tabular}




\section{TABELA I (CONTINUAÇÃO)}

DISTRIBUIÇÕES DAS RESPOSTAS NOS INTERVALOS DE BAIXO, MÉDIO E ALTO DOMÍNIO E IMPORTÂNCIA PARA AMOSTRA DE 447 PARTICIPANTES

\begin{tabular}{|c|c|c|c|c|c|c|c|}
\hline & \multirow{3}{*}{ ITEM } & \multicolumn{6}{|c|}{ DISTRIBUIÇÃO DAS RESPOSTAS (\%) } \\
\hline & & \multicolumn{3}{|c|}{ DOMÍNIO } & \multicolumn{3}{|c|}{ IMPORTÂNCIA } \\
\hline & & BAIXO & MÉDIO & ALTO & BAIXA & MÉDIA & ALTA \\
\hline \multirow{3}{*}{ 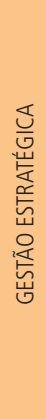 } & $\begin{array}{l}\text { 34. Estabeleço objetivos e metas para a EJ, ponderando urgência } \\
\text { e importância das atividades, bem como a viabilidade de seu } \\
\text { alcance. }\end{array}$ & 2,2 & 14,3 & 83,4 & 0 & 1,1 & 98,9 \\
\hline & $\begin{array}{l}\text { 12. Busco, constantemente, a melhoria dos processos e projetos } \\
\text { da EJ, propondo procedimentos mais efetivos com base em } \\
\text { avaliações. }\end{array}$ & 1,8 & 21,9 & 76,3 & 0,2 & 1,6 & 98,2 \\
\hline & $\begin{array}{l}\text { 21. Avalio a viabilidade da utilização de novas ideias, tecnologias } \\
\text { e ferramentas em atividades da EJ.processos e projetos da } \\
\text { EJ, propondo procedimentos mais efetivos com base em } \\
\text { avaliações. }\end{array}$ & 0,7 & 14,1 & 85,2 & 0 & 1,1 & 98,9 \\
\hline \multirow{8}{*}{ 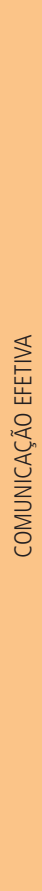 } & $\begin{array}{l}\text { 39. Expresso meu ponto de vista em discussões da EJ, destacando } \\
\text { aspectos relevantes que contribuam para a solução do } \\
\text { problema. }\end{array}$ & 0,7 & 9,6 & 89,7 & 0 & 0,7 & 99,3 \\
\hline & $\begin{array}{l}\text { 31. Repasso informações necessárias ao trabalho de outros } \\
\text { membros da equipe, garantindo a transparência das ações. }\end{array}$ & 0,4 & 6,9 & 92,6 & 0 & 0,7 & 99,3 \\
\hline & $\begin{array}{l}\text { 36. Ao redigir uma mensagem ou documento da EJ, escrevo de } \\
\text { forma objetiva e coesa, garantindo o cumprimento de sua } \\
\text { finalidade. }\end{array}$ & 0,4 & 6,5 & 93,1 & 0,2 & 2,0 & 97,8 \\
\hline & $\begin{array}{l}\text { 35. Indico localização de arquivos e outras fontes de informação } \\
\text { sobre projetos, processos e dados da EJ aos demais membros. }\end{array}$ & 2,5 & 13,4 & 84,1 & 0,4 & 3,6 & 96,0 \\
\hline & $\begin{array}{l}\text { 38. Transmito valores organizacionais aos novos membros, com } \\
\text { foco na continuidade da EJ. }\end{array}$ & 1,3 & 10,7 & 87,9 & 0 & 0,7 & 99,3 \\
\hline & $\begin{array}{l}\text { 24. Auxilio outros membros da EJ, transmitindo conhecimentos } \\
\text { e habilidades relevantes para a execução de suas atividades. }\end{array}$ & 0,4 & 8,7 & 90,8 & 0,4 & 0,2 & 99,3 \\
\hline & $\begin{array}{l}\text { 23. Elogio publicamente ações individuais e coletivas que } \\
\text { contribuam para a melhoria dos processos e se alinhem } \\
\text { aos valores da EJ. }\end{array}$ & 2,2 & 14,1 & 83,7 & 0 & 3,6 & 96,4 \\
\hline & $\begin{array}{l}\text { 29. Ao identificar problemas na EJ, proponho alternativas } \\
\text { adequadas para o alcance dos objetivos da empresa. }\end{array}$ & 0,2 & 11 & 88,8 & 0 & 0,9 & 99,1 \\
\hline
\end{tabular}


TABELA I (CONCLUSÃO)

DISTRIBUIÇÖES DAS RESPOSTAS NOS INTERVALOS DE BAIXO, MÉDIO E ALTO DOMÍNIO E IMPORTÂNCIA PARA AMOSTRA DE 447 PARTICIPANTES

\begin{tabular}{|c|c|c|c|c|c|c|c|}
\hline & \multirow{3}{*}{ ITEM } & \multicolumn{6}{|c|}{ DISTRIBUIÇÃO DAS RESPOSTAS (\%) } \\
\hline & & \multicolumn{3}{|c|}{ DOMÍNIO } & \multicolumn{3}{|c|}{ IMPORTÂNCIA } \\
\hline & & BAIXO & MÉDIO & ALTO & BAIXA & MÉDIA & ALTA \\
\hline \multirow{2}{*}{ 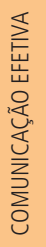 } & $\begin{array}{l}\text { 32. Ao tomar decisões, priorizo os interesses organizacionais } \\
\text { sobre os pessoais, independentemente de vínculos } \\
\text { de amizade com outros membros da EJ. }\end{array}$ & 1,8 & 9,6 & 88,6 & 0,2 & 2,5 & 97,3 \\
\hline & $\begin{array}{l}\text { 11. Ao comunicar decisões importantes, falo de forma clara } \\
\text { e aberta com os membros da EJ. }\end{array}$ & 0,4 & 10,1 & 89,5 & 0,2 & 0,4 & 99,3 \\
\hline \multirow{5}{*}{$\begin{array}{l}\text { 을 } \\
\sum_{\text {岁 }} \\
\sum_{\text {Щे }} \\
\text { 岀 }\end{array}$} & $\begin{array}{l}\text { 7. Adapto-me a diferentes ritmos de trabalho, de aprendizagem } \\
\text { e de produção dos membros da equipe, visando ao alcance } \\
\text { dos objetivos. }\end{array}$ & 0,7 & 11,6 & 87,7 & 0,2 & 2,7 & 97,1 \\
\hline & $\begin{array}{l}\text { 1. Concilio a execução de atividades da EJ com compromissos } \\
\text { da graduação e atividades extra-acadêmicas. }\end{array}$ & 2,5 & 27,5 & 70,0 & 0,4 & 2,7 & 96,9 \\
\hline & $\begin{array}{l}\text { 2. Aprimoro meu desempenho após identificar erros e falhas } \\
\text { na execução do meu trabalho. }\end{array}$ & 0 & 8,3 & 91,7 & 0 & 0,4 & 99,6 \\
\hline & $\begin{array}{l}\text { 8. Aplico na EJ conhecimentos, técnicas e métodos de pesquisa } \\
\text { aprendidos na graduação, adaptando-os às necessidades } \\
\text { da empresa. }\end{array}$ & 2,2 & 22,6 & 75,2 & 0,2 & 5,8 & 94,0 \\
\hline & $\begin{array}{l}\text { 5. Priorizo a execução de projetos alinhados à estratégia } \\
\text { da EJ e que gerem maior benefício para os membros } \\
\text { e para a sociedade. }\end{array}$ & 0,9 & 17,7 & 81,4 & 0 & 3,1 & 96,9 \\
\hline \multirow{5}{*}{ 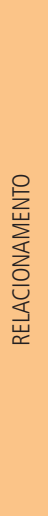 } & $\begin{array}{l}\text { 18. Em situações de discordância, argumento de forma cordial, } \\
\text { considerando as diferentes opiniões. }\end{array}$ & 0,2 & 7,6 & 92,2 & 0 & 0,9 & 99,1 \\
\hline & $\begin{array}{l}\text { 19. Em discussões, avalio os diferentes argumentos apresentados } \\
\text { pelos demais membros da equipe, identificando suas } \\
\text { implicações. }\end{array}$ & 0 & 3,6 & 96,4 & 0 & 0,4 & 99,6 \\
\hline & $\begin{array}{l}\text { 14. Relaciono-me com membros da EJ e outros stakeholders } \\
\text { de forma cordial e educada. }\end{array}$ & 0,2 & 4,3 & 95,5 & 0,2 & 0,7 & 99,1 \\
\hline & $\begin{array}{l}\text { 28. Trabalho cooperativamente, evitando competição } \\
\text { que seja prejudicial à equipe. }\end{array}$ & 0 & 3,6 & 96,4 & 0 & 0,7 & 99,3 \\
\hline & $\begin{array}{l}\text { 4. Demonstro receptividade a novas ideias e conhecimentos } \\
\text { de outras áreas. }\end{array}$ & 0 & 6,0 & 94,0 & 0,2 & 1,1 & 98,7 \\
\hline
\end{tabular}

Fonte: Elaborada pelas autoras. 
A média global na escala de importância foi alta, de 9,27 (DP: I,05). Essa avaliação reflete a baixa variabilidade de resposta aos itens e a indicação de que os respondentes avaliam como alta a importância das competências para o sucesso da EJ. Esse achado pode ser justificado pela adequação do método de coleta utilizado para descrever as competências e gera a reflexão sobre a possibilidade de incluir essas competências nas propostas de disciplinas especificamente elaboradas para atender às demandas de aprendizagem de empresários juniores.

Os valores de domínio também são avaliados como altos com média global de 7,OI (DP: I,63). Todavia, há maior dispersão entre os intervalos, com destaque (em negrito na Tabela 2) para aqueles com presença de pelo menos $20 \%$ de respostas como de médio domínio. Esses itens avaliados como de médio domínio estão dispostos, em sua maioria, nos fatores I, (gestão estratégica da EJ) e 3 (desenvolvimento pessoal). A opção pela descrição de porcentagem de valores por intervalo de respostas pode ser uma alternativa na identificação de grupos de participantes com necessidades específicas, que diferem das necessidades gerais. Entretanto, esse não é o caso desta pesquisa por ter sido garantido o sigilo dos participantes.

No que se refere ao cálculo do IPG, a Tabela 2 traz os itens dispostos em ordem decrescente de valores, além da indicação do respectivo fator.

TABELA 2

IPG DOS ITENS PARA AMOSTRA DE 447 PARTICIPANTES E RESPECTIVOS FATORES

\begin{tabular}{llll}
\hline ITEM & DESCRIÇÃO DO ITEM & FATOR & IPG \\
\hline 22 & $\begin{array}{l}\text { Proponho ações para expansão e desenvolvimento } \\
\text { conjunto da EJ e do MEJ (BJ, federações ou núcleos de EJ), } \\
\text { de acordo com diretrizes e estratégias de ambos. }\end{array}$ & Gestão & $\mathbf{3 2 , 4 4}$ \\
\hline 17 & $\begin{array}{l}\text { Identifico ameaças à comercialização de produtos } \\
\text { e serviços da EJ, considerando as características do mercado. }\end{array}$ & Gestão & $\mathbf{3 1 , 7 8}$ \\
\hline $\begin{array}{l}\text { Busco parcerias e fontes de recursos (financeiros, } \\
\text { materiais e tecnológicos) para a EJ baseadas nos objetivos } \\
\text { organizacionais. }\end{array}$ & Gestão & $\mathbf{3 0 , 0 1}$ \\
\hline $\mathbf{2 6}$ & $\begin{array}{l}\text { Aprimoro produtos e serviços oferecidos pela EJ, } \\
\text { considerando as tendências do seu mercado de atuação. }\end{array}$ & $\mathbf{2 9 , 0 8}$ \\
\hline 16 & $\begin{array}{l}\text { Capto projetos para a EJ, equilibrando a margem de lucro } \\
\text { e as possibilidades de aprendizagem dos membros. }\end{array}$ & Gestão & $\mathbf{2 8 , 5 1}$ \\
\hline
\end{tabular}


TABELA 2 (CONTINUAÇÃO)

IPG DOS ITENS PARA AMOSTRA DE 447 PARTICIPANTES E RESPECTIVOS FATORES

\begin{tabular}{|c|c|c|c|}
\hline ITEM & DESCRIÇÃO DO ITEM & FATOR & IPG \\
\hline 42 & $\begin{array}{l}\text { Ao identificar necessidades do curso que possam ser } \\
\text { supridas com o auxílio da EJ, proponho ações que } \\
\text { beneficiem a empresa, professores e alunos. }\end{array}$ & Gestão & 26,17 \\
\hline 30 & $\begin{array}{l}\text { Relaciono os principais processos do planejamento } \\
\text { estratégico, descrevendo seus componentes (objetivos, } \\
\text { indicadores, planos de ação etc.). }\end{array}$ & Gestão & 25,47 \\
\hline 1 & $\begin{array}{l}\text { Concilio a execução de atividades da EJ com compromissos } \\
\text { da graduação e atividades extra-acadêmicas. }\end{array}$ & Desenvolvimento & 25,40 \\
\hline 12 & $\begin{array}{l}\text { Busco, constantemente, a melhoria dos processos } \\
\text { e projetos da EJ, propondo procedimentos mais efetivos } \\
\text { com base em avaliações. }\end{array}$ & Gestão & 22,10 \\
\hline 41 & $\begin{array}{l}\text { Descrevo os principais processos de gestão de cada área } \\
\text { ou diretoria da EJ, identificando suas interações. }\end{array}$ & Gestão & 21,97 \\
\hline 25 & $\begin{array}{l}\text { Acompanho o alcance de metas que estão sob minha } \\
\text { responsabilidade com base em indicadores de resultados } \\
\text { do plano estratégico da EJ. }\end{array}$ & Gestão & 21,41 \\
\hline 8 & $\begin{array}{l}\text { Aplico na EJ conhecimentos, técnicas e métodos de } \\
\text { pesquisa aprendidos na graduação, adaptando-os às } \\
\text { necessidades da empresa. }\end{array}$ & Desenvolvimento & 20,10 \\
\hline 34 & $\begin{array}{l}\text { Estabeleço objetivos e metas para a EJ, ponderando } \\
\text { urgência e importância das atividades, bem como } \\
\text { a viabilidade de seu alcance. }\end{array}$ & Gestão & 19,59 \\
\hline 5 & $\begin{array}{l}\text { Priorizo a execução de projetos alinhados à estratégia } \\
\text { da EJ e que gerem maior benefício para os membros } \\
\text { e para a sociedade. }\end{array}$ & Desenvolvimento & 19,06 \\
\hline 21 & $\begin{array}{l}\text { Avalio a viabilidade da utilização de novas ideias, } \\
\text { tecnologias e ferramentas em atividades da EJ. }\end{array}$ & Gestão & 18,81 \\
\hline 2 & $\begin{array}{l}\text { Aprimoro meu desempenho após identificar erros } \\
\text { e falhas na execução do meu trabalho. }\end{array}$ & Desenvolvimento & 17,99 \\
\hline
\end{tabular}


TABELA 2 (CONTINUAÇÃO)

IPG DOS ITENS PARA AMOSTRA DE 447 PARTICIPANTES E RESPECTIVOS FATORES

\begin{tabular}{|c|c|c|c|}
\hline ITEM & DESCRIÇÃO DO ITEM & FATOR & IPG \\
\hline 7 & $\begin{array}{l}\text { Adapto-me a diferentes ritmos de trabalho, } \\
\text { de aprendizagem e de produção dos membros da equipe, } \\
\text { visando ao alcance dos objetivos. }\end{array}$ & Desenvolvimento & 17,95 \\
\hline 29 & $\begin{array}{l}\text { Ao identificar problemas na EJ, proponho alternativas } \\
\text { adequadas para o alcance dos objetivos da empresa. }\end{array}$ & Comunicação & 17,54 \\
\hline 23 & $\begin{array}{l}\text { Elogio publicamente ações individuais e coletivas que } \\
\text { contribuam para a melhoria dos processos e se alinhem } \\
\text { aos valores da EJ. }\end{array}$ & Comunicação & 17,22 \\
\hline 35 & $\begin{array}{l}\text { Indico localização de arquivos e outras fontes } \\
\text { de informação sobre projetos, processos e dados da EJ } \\
\text { aos demais membros. }\end{array}$ & Comunicação & 16,45 \\
\hline 40 & Participo ativamente de eventos promovidos pela EJ. & Gestão & 15,83 \\
\hline 32 & $\begin{array}{l}\text { Ao tomar decisões, priorizo os interesses organizacionais } \\
\text { sobre os pessoais, independentemente de vínculos } \\
\text { de amizade com outros membros da EJ. }\end{array}$ & Comunicação & 15,67 \\
\hline 11 & $\begin{array}{l}\text { Ao comunicar decisões importantes, falo de forma clara } \\
\text { e aberta com os membros da EJ. }\end{array}$ & Comunicação & 15,02 \\
\hline 38 & $\begin{array}{l}\text { Transmito valores organizacionais aos novos membros, } \\
\text { com foco na continuidade da EJ. }\end{array}$ & Comunicação & 14,57 \\
\hline 24 & $\begin{array}{l}\text { Auxilio outros membros da EJ, transmitindo conhecimentos } \\
\text { e habilidades relevantes para a execução de suas } \\
\text { atividades. }\end{array}$ & Comunicação & 14,41 \\
\hline 39 & $\begin{array}{l}\text { Expresso meu ponto de vista em discussões da EJ, } \\
\text { destacando aspectos relevantes que contribuam } \\
\text { para a solução do problema. }\end{array}$ & Comunicação & 14,39 \\
\hline 18 & $\begin{array}{l}\text { Em situações de discordância, argumento de forma } \\
\text { cordial, considerando as diferentes opiniões. }\end{array}$ & Relacionamento & 13,54 \\
\hline 4 & $\begin{array}{l}\text { Demonstro receptividade a novas ideias e conhecimentos } \\
\text { de outras áreas. }\end{array}$ & Relacionamento & 13,11 \\
\hline
\end{tabular}


TABELA 2 (CONClUSÃo)

IPG DOS ITENS PARA AMOSTRA DE 447 PARTICIPANTES E RESPECTIVOS FATORES

\begin{tabular}{llll}
\hline ITEM & DESCRIÇÃO DO ITEM & FATOR & IPG \\
\hline 31 & $\begin{array}{l}\text { Repasso informações necessárias ao trabalho de outros } \\
\text { membros da equipe, garantindo a transparência das ações. }\end{array}$ & Comunicação & 13,08 \\
\hline & $\begin{array}{l}\text { Em discussões, avalio os diferentes argumentos } \\
\text { apresentados pelos demais membros da equipe, } \\
\text { identificando suas implicações. }\end{array}$ & Relacionamento & 11,58 \\
\hline & $\begin{array}{l}\text { Ao redigir uma mensagem ou documento da EJ, escrevo } \\
\text { de forma objetiva e coesa, garantindo o cumprimento } \\
\text { de sua finalidade. }\end{array}$ & Comunicação & 10,72 \\
\hline 28 & $\begin{array}{l}\text { Trabalho cooperativamente, evitando competição } \\
\text { que seja prejudicial à equipe. }\end{array}$ & Relacionamento & 9,73 \\
\hline 14 & $\begin{array}{l}\text { Relaciono-me com membros da EJ e outros stakeholders } \\
\text { de forma cordial e educada. }\end{array}$ & Relacionamento & 7,97 \\
\hline
\end{tabular}

Fonte: Elaborada pelas autoras.

De modo geral, os valores do IPG foram baixos pelo fato de as respostas às escalas de domínio e importância terem sido altas, o que levou à identificação de poucas necessidades de treinamento. Assim, optou-se por utilizar o valor 25 não como um ponto de corte, e sim como um valor que classificaria as necessidades de treinamento como prioritárias, ou não prioritárias.

As necessidades identificadas como prioritárias pertencem aos fatores I (gestão estratégica da EJ) e 3 (desenvolvimento pessoal) e referem-se a: desenvolvimento conjunto das EJs e do Movimento de Empresas Juniores (MEJ), análise de oportunidades e de ameaças à expansão do negócio das EJs, busca de parcerias e fontes de recursos, aprimoramento de produtos e serviços, captação de projetos, compreensão dos elementos do planejamento estratégico e gerenciamento do tempo.

Por sua vez, as necessidades identificadas como de menor prioridade referem-se a competências de cunho relacional e social, clareza ao se comunicar de maneira oral e escrita, abertura a novos conhecimentos e a forma de trabalhar cooperativamente. Essas necessidades concentram-se nos fatores 2 (comunicação efetiva) e 4 (relacionamento cooperativo). 
Essa conjugação das escalas de importância e domínio para cálculo do IPG, conforme proposto por Borges-Andrade e Lima (1983), foi considerada uma solução parcial para identificar necessidades de treinamento. Por causa da pequena variabilidade das respostas dos participantes em ambas as escalas, não foi possível também identificar variações expressivas para os valores de IPG gerados, o que levou, por consequência, à identificação de poucas necessidades de treinamento prioritárias.

Discute-se se essa pequena variabilidade de respostas especificamente para a escala de domínio foi efeito de um domínio realmente alto das competências pelos participantes (o que implicaria ausência de necessidades de treinamento), de uma possível supervalorização pelos empresários juniores quanto ao nível de domínio dessas competências ou da inadequação do método de operacionalização da ANT que pode ter facilitado a leniência dos participantes em razão da amplitude das escalas utilizadas e da definição de pontos extremos considerados ideais ou indesejáveis.

\subsection{ESTUDO II}

O estudo II teve o objetivo de descrever os principais desafios e mudanças que empresários juniores enfrentam na sua rotina de atividades e execução de projetos. Para alcançar esse objetivo, foram realizadas entrevistas coletivas com empresários juniores e entrevistas individuais com profissionais e docentes.

Os resultados apresentados entre essas duas amostras tiveram algumas convergências, conforme apresentado no Quadro I. Além dessas convergências, os profissionais não juniores identificaram um rol mais extenso de desafios e mudanças que estão destacados no Quadro 2. Os empresários juniores, por sua vez, muitas vezes relataram metas organizacionais como desafios e mudanças. Essas metas também foram analisadas e estão sistematizadas no Quadro 3.

Sobre os desafios e as mudanças relatados tanto por empresários juniores quanto por profissionais, destacam-se quatro categorias de conteúdo. Cada verbalização referente a determinado conteúdo contou como uma ocorrência nas frequências, sendo o total de verbalizações equivalente, portanto, ao somatório das frequências. O Quadro I apresenta essas categorias, a contagem de respostas e os componentes descritivos. 
QUADRO I

DESAFIOS E MUDANÇAS RELATADOS TANTO POR EMPRESÁRIOS JUNIORES, QUANTO POR PROFISSIONAIS E DOCENTES

\begin{tabular}{|c|c|}
\hline CATEGORIAS & DESAFIOS OU MUDANÇAS \\
\hline $\begin{array}{l}\text { Consolidação da } \\
\text { imagem do MEJ } \\
\left(N^{\circ}=34\right)\end{array}$ & $\begin{array}{l}\text { Divulgar o que é o MEJ e as EJs, seus objetivos, seus trabalhos e sua } \\
\text { capacidade formadora para a comunidade acadêmica, mercado e } \\
\text { sociedade; tornar a imagem das EJs reconhecidas e respeitadas em } \\
\text { âmbito local, regional e nacional; integrar EJs, núcleos, federações } \\
\text { e confederação. }\end{array}$ \\
\hline $\begin{array}{l}\text { Consolidação } \\
\text { institucional } \\
\left(\mathrm{N}^{\circ}=27\right)\end{array}$ & $\begin{array}{l}\text { Consolidação institucional do MEJ e de sua estratégia; reconhecimento } \\
\text { da capacidade formadora do MEJ pelas IESs e pelo MEC; fomento } \\
\text { de uma rede de apoio ao MEJ entre discentes, docentes, mercado } \\
\text { e sociedade; formalização do status das EJs nas grades curriculares } \\
\text { dos cursos; formalização do papel dos professores nas orientações } \\
\text { de projeto e dos benefícios a serem recebidos por essas supervisões; } \\
\text { formalização do vínculo de apoio entre EJs e departamento de ensino. }\end{array}$ \\
\hline $\begin{array}{l}\text { Transição e } \\
\text { gestão do } \\
\text { conhecimento } \\
\left(\mathrm{N}^{\circ}=25\right)\end{array}$ & $\begin{array}{l}\text { Manutenção do ritmo de desenvolvimento da EJ e da execução } \\
\text { de sua estratégia mesmo com a rotatividade de integrantes gerada } \\
\text { a cada troca de gestão; gerenciamento do conhecimento, ferramentas } \\
\text { e tecnologias produzidas na realização dos projetos durante períodos } \\
\text { de transição entre gestões; estabilidade da confiança do mercado quanto } \\
\text { à qualidade dos projetos realizados pela EJ ao longo do tempo. }\end{array}$ \\
\hline $\begin{array}{l}\text { Suporte material } \\
\left(\mathrm{N}^{\circ}=9\right)\end{array}$ & $\begin{array}{l}\text { Conquista e/ou ampliação do espaço físico; aquisição e/ou renovação } \\
\text { de equipamentos que viabilizem a realização de atividades da EJ. }\end{array}$ \\
\hline
\end{tabular}

Fonte: Elaborado pelas autoras.

A categoria que apresentou maior frequência de respostas foi "consolidação da imagem do MEJ" e refere-se ao desafio de construir e divulgar uma imagem positiva do MEJ para a comunidade acadêmica, o mercado e a sociedade, de forma a facilitar a concretização dos objetivos. O esperado é que uma imagem positiva viabilize maior apoio institucional, especialmente dos professores e departamento de ensino, e atraia novos alunos que queiram se integrar às EJs. Esse desafio exigirá a mobilização de todas as esferas do MEJ para a determinação de padrões e normas comuns e compatíveis com EJs de realidades diversas. A superação desses desafios poderá levar a um crescimento mais homogêneo do MEJ brasileiro.

A segunda categoria com maior número de frequência de respostas foi "consolidação institucional” que se refere à necessidade de valorizar a capacidade 
formadora do MEJ por meio da consolidação de vínculos de apoio, incentivo e reconhecimento pelas IES, departamentos de ensino, professores e pelo Ministério da Educação (MEC). O apoio desses agentes pode servir como facilitador do processo de aprendizagem e formalizar o papel das EJs como espaços de formação complementar e prática do que é aprendido em sala de aula.

A categoria "transição e gestão do conhecimento" refere-se ao desafio de manter o crescimento e a qualidade dos serviços prestados durante a troca de gestões, para que isso aconteça sem ruptura mesmo com a rotatividade de membros. As contínuas trocas de gestões parecem ser inevitáveis por causa da dinâmica dessas organizações. Entretanto, ações para gerir o conhecimento produzido e estipular períodos de transição ou cogestão parecem ser alternativas viáveis para inibir perdas e rupturas.

A categoria "suporte material" engloba desafios não sanáveis por meio de ações educacionais (Abbad, Zerbini et al., 2006; Freitas \& Brandão, 2006; Le Boterf, 2003) e que podem restringir a manifestação de competências. Esse desafio refere-se à necessidade de conquistar e/ou ampliar espaço físico e adquirir e/ou renovar equipamentos que viabilizem a realização das atividades da EJ.

Sobre os desafios e as mudanças relatados apenas pelos profissionais e docentes, destacam-se seis categorias. Essas categorias de conteúdo são mais amplas e mostraram-se mais específicas e detalhadas para análise do contexto global em que as EJs se inserem. O Quadro 2 apresenta essas categorias, sua contagem de respostas e seus componentes descritivos.

\section{QUADRO 2}

\section{DESAFIOS E MUDANÇAS RELATADOS APENAS} POR PROFISSIONAIS NÃO JUNIORES

\begin{tabular}{|c|c|}
\hline CATEGORIAS & DESAFIOS OU MUDANÇAS \\
\hline $\begin{array}{l}\text { Padronização } \\
\left(N^{\circ}=16\right)\end{array}$ & $\begin{array}{l}\text { Padronização quanto aos principais objetivos do MEJ e de suas } \\
\text { prioridades, clientes-alvo das EJs e os padrões de lucratividade do negócio, } \\
\text { e tipo de recompensa recebida pelos empresários juniores na realização } \\
\text { de projetos; estabelecimento de um nível mínimo na qualidade dos } \\
\text { projetos das EJs; diferenciação das EJs de empresas seniores no mercado } \\
\text { e de sua real capacidade de entrega; definição da função das EJs } \\
\text { com relação ao fomento e à difusão da inovação e de uma cultura } \\
\text { empreendedora no país. }\end{array}$ \\
\hline
\end{tabular}

(continua) 
QUADRO 2 (CONCLUSÃO)

DESAFIOS E MUDANÇAS RELATADOS APENAS POR PROFISSIONAIS NÃO JUNIORES

\begin{tabular}{|c|c|}
\hline CATEGORIAS & DESAFIOS OU MUDANÇAS \\
\hline $\begin{array}{l}\text { Atualização } \\
\left(\mathrm{N}^{\circ}=4\right)\end{array}$ & $\begin{array}{l}\text { Acompanhamento e participação das evoluções na área de atuação; } \\
\text { acompanhamento dos debates sobre os espaços de atuação da área } \\
\text { profissional e limites de outras áreas; atualização de competências } \\
\text { técnicas para acompanhar o dinamismo das demandas do mercado. }\end{array}$ \\
\hline $\begin{array}{l}\text { Modelo de } \\
\text { negócio } \\
\left(\mathrm{N}^{\circ}=4\right)\end{array}$ & $\begin{array}{l}\text { Elaboração de modelo de negócio específico para a realidade das EJs; } \\
\text { especialização na prestação de serviços ou elaboração de produtos } \\
\text { de fácil reprodução e de maior aceitação e alcance de mercado; } \\
\text { desenvolvimento de modelos próprios à realidade do MEJ que não } \\
\text { forcem a replicação de padrões. }\end{array}$ \\
\hline $\begin{array}{l}\text { Competitividade } \\
\left(\mathrm{N}^{\circ}=3\right)\end{array}$ & $\begin{array}{l}\text { Aumento da competitividade das EJs no mercado; diminuição } \\
\text { da competitividade entre as EJs de atuação semelhante. }\end{array}$ \\
\hline $\begin{array}{l}\text { Reuni } \\
\left(N^{\circ}=2\right)\end{array}$ & $\begin{array}{l}\text { Adaptação das EJs ao Reuni no que se refere a expansão da infraestrutura, } \\
\text { aumento do número de alunos integrantes das EJ, aumento do número } \\
\text { de professores orientadores e necessidade de maior apoio institucional. }\end{array}$ \\
\hline $\begin{array}{l}\text { Regulamentação } \\
\left(\mathrm{N}^{\circ}=2\right)\end{array}$ & Elaboração de uma legislação reguladora do MEJ no Brasil. \\
\hline
\end{tabular}

Fonte: Elaborado pelas autoras.

A categoria "padronização" refere-se ao desafio de unificar a identidade MEJ por meio da definição de suas prerrogativas, diretrizes, estratégias e diferenciais. Esse desafio envolverá uma mobilização nacional dos empresários juniores para uma maior equalização das ações, diretrizes e propostas.

A categoria "atualização" refere-se ao desafio de promover uma educação continuada dentro do ambiente das EJs, de modo a potencializar as experiências dos empresários juniores. Esse desafio remete à intenção de promover educação profissional ampla e crítica, o que pode ser estendido para a sala de aula, demais atividades acadêmicas e a vida profissional futura desses alunos.

A categoria "modelo de negócio" refere-se ao desafio de revisar a estrutura organizacional e produtiva das EJs, de modo a buscar uma maior efetividade de suas práticas. Esse desafio implicará a opção por manter ou redefinir o padrão de prestação de serviços em prática na maioria das EJs do país.

A categoria "competitividade" refere-se ao desafio de as EJs manterem-se competitivas no mercado e terem seus negócios diferenciados entre as que possuem 
atuações semelhantes. A categoria Reestruturação e Expansão das Universidades Federais (Reuni) aponta para as possíveis alterações que esse programa trará para as IES e que gerará demandas por maior disponibilidade de recursos físicos e humanos, como salas maiores para o funcionamento das EJs e aumento no número de professores supervisores dos projetos realizados por elas.

A categoria "regulamentação" refere-se ao desafio de elaborar legislação que regulamente o MEJ e suas ações. A "regulamentação" também poderá tratar da estipulação de critérios de competitividade no mercado e entre EJs que sejam coerentes com as propostas do MEJ. Nesse sentido, o Projeto de Lei n. 437 (20I2) que tramita no Senado Federal, cujo objetivo é regulamentar a criação e o funcionamento das EJs do país, tem potencial para sanar esse desafio.

Sobre os desafios e as mudanças relatados apenas por empresários juniores, destacam-se quatro categorias, conforme apresentado no Quadro 3. As análises do teor dessas categorias de conteúdo fazem referência muito mais a resultados e metas almejados do que propriamente a desafios e mudanças em curso que podem afetar as práticas educacionais dessas organizações. Esses achados indicam a visão dos empresários juniores de que metas, desafios e mudanças podem ser identificados como elementos similares, possivelmente pelas dificuldades em alcançar as metas atuais estabelecidas.

\section{QUADRO}

\section{DESAFIOS E MUDANÇAS RELATADOS APENAS POR EMPRESÁRIOS JUNIORES}

\begin{tabular}{|c|c|}
\hline CATEGORIAS & DESAFIOS E MUDANÇAS \\
\hline $\begin{array}{l}\text { Conquistar } \\
\text { mercado } \\
\left(\mathrm{N}^{\circ}=26\right)\end{array}$ & $\begin{array}{l}\text { Buscar posição de destaque na área de atuação, conquistando a confiança } \\
\text { do mercado; diversificar em produtos e projetos; ampliar parcerias } \\
\text { e relações com stakeholders; ampliar número de clientes e a capacidade } \\
\text { produtiva da EJ; buscar constante melhoria na qualidade dos serviços } \\
\text { prestados e a fidelidade dos clientes. }\end{array}$ \\
\hline $\begin{array}{l}\text { Aperfeiçoar } \\
\text { processos } \\
\text { internos } \\
\left(\mathrm{N}^{\circ}=22\right)\end{array}$ & $\begin{array}{l}\text { Aperfeiçoar práticas e processos de gestão; formular e executar } \\
\text { a estratégia do negócio; estruturar o agendamento de atividades; promover } \\
\text { ambiente de trabalho adequado; firmar estabilidade administrativa } \\
\text { e financeira; aprimorar negociação com clientes; estruturar cargos } \\
\text { e diretorias; fomentar a inovação e criatividade; viabilizar crescimento } \\
\text { de acordo com aumento de demanda. }\end{array}$ \\
\hline
\end{tabular}

(continua) 
QuAdro 3 (CONCLUSÃo)

DESAFIOS E MUDANÇAS RELATADOS APENAS

POR EMPRESÁRIOS JUNIORES

\begin{tabular}{ll}
\hline CATEGORIAS & DESAFIOSE MUDANÇAS \\
\hline $\begin{array}{l}\text { Desenvolver } \\
\text { membros } \\
\left(N^{\circ}=18\right)\end{array}$ & $\begin{array}{l}\text { Promover desenvolvimento e atualização de competências técnicas, } \\
\text { entregas; administrar tempo; promover treinamento introdutório de novos } \\
\text { membros; inibir que eventuais quedas na qualidade do curso impactem a } \\
\text { qualidade dos serviços prestados. }\end{array}$ \\
$\begin{array}{l}\text { Questões } \\
\text { motivacionais } \\
\left(N^{\circ}=2\right)\end{array}$ & $\begin{array}{l}\text { Conciliar a quantidade de atividades dos membros e sua qualidade de } \\
\text { vida; fomentar o comprometimento dos membros. }\end{array}$ \\
\hline
\end{tabular}

Fonte: Elaborado pelas autoras.

A categoria "conquistar mercado" refere-se à meta de buscar posição de destaque na área de atuação, conquistando a confiança do mercado e buscando competitividade. As metas de buscar aperfeiçoamento de processos e procedimentos da gestão da EJ e da realização de seus projetos evidencia-se na categoria "aperfeiçoar processos internos". As metas de promover desenvolvimento e atualização das competências dos membros da EJ está presente na categoria "desenvolver membros".

Por fim, foi apontada como meta a categoria "questões motivacionais" que engloba aspectos, a exemplo de "suporte material", como não sanáveis por meio de ações educacionais. Promoção de comprometimento com o trabalho e equalização entre quantidade de atividades e qualidade de vida não são elementos passíveis de ser trabalhados via ação educacional.

Os desafios e as mudanças identificados são diversos. A necessidade de elaborar um eixo comum de padronização do MEJ e de sua regulamentação poderá gerar necessidades por treinamentos que abordem a revisão nas políticas e nos processos das EJs de todo o país.

A revisão do modelo de negócio e do formato de competitividade das EJs gerará necessidades de treinamento que capacitem os empresários juniores dentro das novas práticas adotadas. A integração de ações de educação continuada poderá levar a uma elaboração de programas de aprendizagem contínua com necessidades de treinamento sendo identificadas e trabalhadas com base em um plano educacional mais amplo e de longo prazo.

A estipulação de ações que minimizem perdas de conhecimento decorrentes de trocas de gestão poderá diminuir as necessidades de treinamento de 
novos integrantes das EJs e impactar a manutenção da qualidade dos serviços prestados. Os outros desafios e mudanças apontados referem-se a problemas de suporte oferecido às EJs, tal qual espaço físico e apoio institucional que possuem impacto direto na manifestação de competências. Esses desafios e mudanças exigirão a mobilização do MEJ em níveis local, regional e nacional para serem superados.

Apresentados os resultados alcançados, segue-se para a conclusão desses achados, considerando a perspectiva teórica e metodológica de referência.

\section{CONCLUSÃO}

Com base nos resultados desta pesquisa, é possível concluir que as EJs oportunizam o desenvolvimento de competências de importância para o mercado de trabalho e exigem alta complexidade em sua manifestação. Sua descrição como necessidades de treinamento baseadas em objetivos instrucionais mostrou-se efetiva para melhor precisar a convergência teórica entre competências e necessidades de treinamento, e para integrar o planejamento, a execução e a avaliação do treinamento.

A adoção do modelo teórico de Abbad e Mourão (20I2) norteou a identificação de desafios e mudanças que podem gerar novas necessidades de treinamento. Isso pode contribuir para o avanço da área ao propor uma análise sistemática de fatores que podem gerar futuras necessidades de treinamento a serem sanadas com base em um plano estratégico de treinamento e desenvolvimento. A intenção é expandir a abordagem diagnóstica que foca as necessidades atuais que já impactam o nível de excelência de desempenho do indivíduo e integrá-la a uma perspectiva preventiva e estratégica em que melhor se estruturam os planos de ação educacional ao longo do tempo.

$\mathrm{O}$ fato de os itens mais bem avaliados para domínio se referirem à comunicação efetiva e a relacionamentos cooperativos pode decorrer da própria experiência que o aluno tem na EJ ou de experiências em outras atividades extracurriculares que geram desenvolvimento em capacidades sociais e relacionais. Por sua vez, os itens de menor domínio estão relacionados a competências de gestão estratégica da EJ e de gerenciamento pessoal do tempo, aspectos que indicam a dificuldade de atuar de maneira estratégica e perene. Também se observa que essas competências de menor domínio não são sistematicamente enfatizadas nas propostas didáticas proporcionadas em sala de aula.

Esses achados indicam, portanto, a necessidade de estimular a adoção de estratégias de ensino-aprendizagem focadas em análises de problemas reais que 
incluem estudos de cenários externos, suporte institucional e trabalho em equipe. A formação tradicional focada no desenvolvimento de competências individuais parece não atender às necessidades da sociedade que exige profissionais capazes de resolver problemas complexos.

Em temos de contribuições, esta pesquisa forneceu embasamento para a melhoria da efetividade dos processos da área de ANT por meio de um estudo empírico baseado em um modelo teórico que propõe análises prognósticas de necessidades de treinamento com base na identificação de desafios e mudanças. A pesquisa também avançou na compreensão da operacionalização da ANT e de sua integração com os demais subsistemas instrucionais.

No que se refere às implicações práticas, a pesquisa possibilitou a realização de uma ANT no contexto de EJs, contexto ainda pouco estudado, atendendo à demanda por análises mais sistemáticas sobre as especificidades e realidade dessas organizações. As necessidades identificadas como prioritárias referem-se a comportamentos de alta complexidade que demandarão o uso de estratégias de ensino e recursos instrucionais que simulem situações da prática profissional dos empresários juniores. A inclusão de disciplinas de outras áreas do conhecimento, principalmente da Administração, também pode colaborar para sanar muitas das necessidades de treinamento identificadas.

Do ponto de vista social, foi possível fornecer embasamento para a melhoria da efetividade dos processos e práticas das EJs, de modo a estimular o desenvolvimento das competências dos empresários juniores brasileiros, o que irá repercutir no seu aperfeiçoamento profissional e no aprimoramento da prestação de serviços à sociedade.

Como limitação deste estudo, destacam-se, principalmente, a pouca efetividade das escalas e do método de cálculo de IPG utilizados para diferenciar necessidades de treinamento prioritárias e a impossibilidade de precisar quais necessidades de treinamento serão geradas a partir dos desafios e das mudanças identificados.

Por fim, como agenda de pesquisa, sugerem-se: I. o aperfeiçoamento do método para precisar futuras demandas de aprendizagem relacionadas a desafios e mudanças específicos; 2. a ampliação da coleta de dados que relacionem as necessidades de treinamento a dados sociodemográficos; 3. a conjugação de auto e heteroavaliação em novas aplicações do questionário; 4. a investigação de variáveis duras (como produtividade e rotatividade) na realização da ANT para colaborar na consolidação de ações instrucionais; e 5. a ampliação da pesquisa com a participação de outros stakeholders (como clientes e parceiros) das EJs. 


\section{TRAINING NEEDS: A PROPOSAL FOR A STRATEGIC EVALUATION IN THE CONTEXT OF JUNIOR BRAZILIAN ENTERPRISES}

\section{ABSTRACT}

The analysis of the literature points to be necessary to carry out empirical research based on the propositions and theoretical models of training needs assessment (TNA). There are no reports of training needs in the context of Junior Enterprises (JEs), organizations that contribute to the professional training of students in higher education. The research objective was to analyze the training needs of junior Brazilian entrepreneurs and identify the challenges and changes faced by JEs that can generate future demands for training. Two studies were carried out. Study I identified the training needs of a sample of junior entrepreneurs and was carried out in four steps: I. design a TNA questionnaire of 43 items associated with scales of II points for domain and importance, 2. semantic validation, 3. use in a sample of 447 junior entrepreneurs from all over the country, and 4. analysis of data to identify priority training needs. Study II identified the challenges and changes experienced by the JEs that can generate future training needs for junior entrepreneurs and it involved the following steps: I. design of semi-structured interview script, 2. individual interviews with a sample of 2I professionals and professors, 3. collective interviews with 34 junior entrepreneurs; and 4. analysis of data for categorization and description of challenges and changes. The findings of Study I indicate that the priority training needs refer to strategic JE management capacities and personal time management; and those of lower priority refer to effective communication and the ability to establish cooperative relationships. The results of Study II describe diverse challenges and changes, better specified by the sample of professionals and professors, and that can generate future training needs. It discusses the possibility to promote strategically developed training actions, involving the improvement of the activities and projects of the junior entrepreneurs, and the offering of top quality of products and services. This research contributes to the advancement of an integrated view between diagnostic and prognosis analyses of training needs, although within limited precision.

\section{KEYWORDS}

Training needs. Junior entrepreneurs. Competences. Context. Professional development. 


\section{NECESIDADES DE CAPACITACIÓN: UNA PROPUESTA DE EVALUACIÓN ESTRATÉGICA EN EL CONTEXTO DE LAS EMPRESAS JUNIORES BRASILEÑAS}

\section{RESUMEN}

El análisis de la literatura señala la necesidad de llevar a cabo investigación empírica basada en las propuestas y modelos teóricos de la Evaluación de Necesidad de Capacitación (ENC). No hay ningún informe de identificación de necesidades de formación en el contexto de Empresas Juniores (EJs), organizaciones que contribuyen a la formación profesional de estudiantes de educación superior. El objetivo de esta investigación fue analizar las necesidades de formación de empresarios juniores brasileños e identificar los retos y cambios que enfrentan las EJs que pueden generar las demandas futuras de capacitación. Fueron realizados dos estudios. El Estudio I identificó las necesidades de formación de una muestra de empresarios juniores y se realizó en cuatro etapas: I. diseño de un cuestionario de ENC con 43 ítems relacionados con escalas de iI puntos para el dominio e importancia, 2. validación semántica, 3. uso en una muestra de 447 empresarios juniores de todo el país y 4. análisis de datos para identificar las necesidades de formación prioritarias. El Estudio II identificó los retos y cambios experimentados por las EJs y que pueden generar futuras necesidades de capacitación para empresarios juniores e incluyó las siguientes etapas: I. diseño del guión de entrevista semi-estructurada, 2. entrevistas individuales con una muestra de 2 I profesionales y docentes, 3 . entrevistas colectivas con una muestra de 34 empresarios juniores; y 4. análisis de datos para clasificación y descripción de los retos y cambios. Los resultados del Estudio I indican que las necesidades que tienen prioridad se refieren a capacidades de gestión estratégica de la Ej y gestión del tiempo personal; y las de menor prioridad se refieren a una comunicación efectiva y a la capacidad de establecer relaciones de cooperación. Los resultados del Estudio II describen retos y cambios diversos, mejor especificados por la muestra de profesionales y docentes, y que pueden generar necesidades de capacitación futuras. Se discute la posibilidad de promover acciones de formación desarrolladas estratégicamente que impliquen la mejora de las actividades y proyectos de los empresarios juniores y en ofrecer servicios y productos de calidad superior. Se contribuyó para el avance de una visión integrada entre análisis diagnósticos y pronósticos de necesidades de capacitación, aunque con limitada precisión. 


\section{PALABRAS CLAVE}

Necesidades de formación. Empresarios juniores. Competencias. Contexto. Desarrollo profesional.

\section{REFERÊNCIAS}

Abbad, G. S. (2009). Avaliação de necessidades e avaliação de impactos de programas de treinamento presenciais e a distância em organizações e trabalho (Pedido de renovação de bolsa de produtividade CNPQ), Brasília, DF, Programa de Pós-Graduação em Psicologia Social, do Trabalho e das Organizações, Instituto de Psicologia, Universidade de Brasília.

Abbad, G. S., \& Borges-Andrade, J. E. (2004). Aprendizagem humana em organizações e trabalho. In J. C. Zanelli, J. E. Borges-Andrade \& A. V. B. Bastos (Orgs.). Psicologia, organizações e trabalho no Brasil (pp. 237-275). Porto Alegre: Artmed.

Abbad G. S., Coelho, F. A., Jr., Freitas, I. A., \& Pilati, R. (2006). Medidas de suporte em avaliação de TD\&E. In J. E. Borges-Andrade, G. S. Abbad \& L. Mourão (Orgs.). Treinamento, desenvolvimento e educação em organizações de trabalho: fundamentos para a gestão de pessoas (pp. 395-42I). Porto Alegre: Artmed.

Abbad G. S., Freitas, I. A., \& Pilati, R. (2006). Contexto de trabalho, desempenho competente e necessidades em TD\&E. In J. E. Borges-Andrade, G. S. Abbad \& L. Mourão (Orgs.). Treinamento, desenvolvimento e educação em organizações de trabalho: fundamentos para a gestão de pessoas (pp. 23I-254). Porto Alegre: Artmed.

Abbad, G. S., \& Mourão, L. (20I2). Avaliação de necessidades de TD\&E: proposição de um novo modelo. Revista de Administração Mackenzie, 13(6), I07-I37.

Abbad, G. S., Zerbini, T., Carvalho, R. S., \& Meneses, P. P. M. (2006). Planejamento instrucional em TD\&E. In J. E. Borges-Andrade, G. S. Abbad \& L. Mourão (Orgs.). Treinamento, desenvolvimento e educação em organizações de trabalho: fundamentos para a gestão de pessoas (pp. 289-32I). Porto Alegre: Artmed.

Aguinis, H., \& Kraiger, K. (2009). Benefits of training and development for individuals and teams, organizations, and society. Annual Review of Psychology, 60, 45I-474.

Ajjawi, R., Thistlethwaite, J. E., Aslani, P., \& Cooling, N. B. (2010). What are the perceived learning needs of Australian general practice registrars for quality prescribing? Medical Education, 10(92), I-7. Akhtar-Danesh, N., Valaitis, R. K., Schofield, R., Underwood, J., Martin-Misener, R., Baumann, A., \& Kolotylo, C. (2010). A questionnaire for assessing community health nurses' learning needs. Western Journal of Nursing Research, 32(8), 1055-1072.

Ateudjieu, J., Williams, J., Hirtle, M., Baume, C., Ikingura, J., Niaré, A., \& Sprumont, D. (2010). Training needs assessment in research ethics committee members in three African countries: Cameroon, Mali and Tanzania. Developing World Bioethics, 10(2), 88-98.

Bardin, L. (2002). Análise de conteúdo. Lisboa: Edições 70.

Bloom, B. S., Engelhart, M. D., Furst, E. J., Hill, W. H., \& Krathwohl, D. R. (1976). Taxonomia de objetivos educacionais: domínio cognitivo. Porto Alegre: Globo. 
Bloom, B. S., Krathwohl, D. R., \& Masia, B. B. (I973). Taxonomia de objetivos educacionais: domínio afetivo. Porto Alegre: Globo.

Borges-Andrade, J. E. (2006). Avaliação integrada e somativa em TD\&E. In J. E. Borges-Andrade, G. S. Abbad \& L. Mourão (Orgs.). Treinamento, desenvolvimento e educação em organizações de trabalho: fundamentos para a gestão de pessoas (pp. 343-358). Porto Alegre: Artmed.

Borges-Andrade, J. E., \& Lima, S. V. (I983). Avaliação de necessidades de treinamento: um método de análise de papel ocupacional. Tecnologia Educacional, 12(54), 6-22.

Borges-Andrade, J. E., Lima, S. V., Soares, C. R. V., \& Paula, S. M. A. (1989). Treinamento de gerentes de pesquisa: necessidades e impacto. Cadernos de Difusão de Tecnologia, 6(I), II7-I39.

Brandão, H. P., Guimarães, T. A., \& Borges-Andrade, J. E. (2002). Competências emergentes na indústria bancária. Revista Comportamento Organizacional e Gestão, 8(2), I73-I90.

Brasil Júnior (2008). Conceito nacional de empresa júnior. Recuperado em I5 julho, 20II, de http://www.riojunior.com.br/adm/arquivo/Conceito_Nacional_de_Empresa_Juniorıo.pdf

Brasil Júnior. (2009). DNA júnior. Recuperado em I5 julho, 20II, de www.brasiljunior.org.br/ arquivos/download/34.

Brasil Júnior (2010). Relatório Nacional Censo e Identidade 20I0. Recuperado em I5 julho, 20II, de http://www.brasiljunior.org.br/site/category/8-arquivos-gerais.

Brasil Júnior (20II). Sistema Brasil Júnior. Recuperado em I5 julho, 20II, de http://www.brasiljunior.org.br.

Brasil Júnior (20I2). Relatório Nacional Censo e Identidade 20II. Recuperado em I5 julho, 20II, de http://www.brasiljunior.org.br/site/arquivos/download/24.

Campos, E. B. D. (2012). Avaliação de necessidades de treinamento de empresários juniores brasileiros. Dissertação de mestrado, Universidade de Brasília, Brasília, DF, Brasil.

Carlisle, J., Bhanugopan, R., \& Fish, A. C. (20II). Training needs of nurses in public hospitals in Australia: review of current practices and future research agenda. Journal of European Industrial Training, 35(7), 687-70I.

Castro, P. M. R., \& Borges-Andrade, J. E. (2004). Identificação das necessidades de capacitação profissional: o caso dos assistentes administrativos da Universidade de Brasília. Revista de Administração da USP, 39(I), 96--108.

Cofré, H., Camacho, J., Galaz, A., Jiménez, J., Santibáñez, D., \&Vergara, C. (2010). La educación científica en Chile: debilidades de la enseñanza y futuros desafios de la educación de profesores de ciencia. Estudios pedagógicos, 36(2), 279-293.

Ferreira, R. (2009). Avaliação de necessidades de treinamento: proposição e aplicação de um modelo teórico-metodológico nos níveis macro e meso organizacionais. Dissertação de mestrado, Universidade de Brasília, Brasília, DF, Brasil.

Ferreira, R., Abbad, G., Pagotto, C., \& Meneses, P. (2009). Avaliação de necessidades organizacionais de treinamento: o caso de uma empresa latino-americana de administração aeroportuária. Revista Eletrônica de Administração, 15(2), I-26.

Freitas, I. A., \& Brandão, H. P. (2006). Trilhas de aprendizagem como estratégia de TD\&E. In J. E. Borges-Andrade, G. S. Abbad \& L. Mourão (Orgs.). Treinamento, desenvolvimento e educação em organizações de trabalho: fundamentos para a gestão de pessoas (pp. 97-II3). Porto Alegre: Artmed.

Goldstein, I. L. (I980). Training in work organizations. Annual Review of Psychology, 31, 229-272. 
Hoffman-Câmara, R., Abbad, G. S., Meneses, M. P. P., \& Ferreira, R. R. (2010). Necessidades educacionais complementares do bacharel em Turismo: aplicação do método da análise do papel ocupacional. Revista de Turismo e Patrimônio Cultural, 8(2), 305-318.

Iqbal, M. Z., \& Khan, R. A. (20II). The growing concept and uses of training needs assessment: a review with proposed model. Journal of European Industrial Training, 35(5), 439-466.

Kozlowski, S. W. J., Brown, K. G., Weissbein, D. A., Cannon-Bowers, J. A., \& Salas, E. (2000). A multilevel approach to training effectiveness: enhancing horizontal and vertical transfer. In K. J. Klein \& S. W. J. Kozlowski (Eds.). Multilevel theory, research, and methods in organizations: foundations, extensions, and new directions (pp. 157-210). San Francisco: Jossey-Bass.

Latham, G. P. (1988). Human resource training and development. Annual Review of Psychology, 39(I), 545-582.

Le Boterf, G. (2003). Desenvolvendo as competências dos profissionais. Porto Alegre: Artmed.

Lima, S. V., Castro, A. G., \& Machado, M. S. (2004, outubro). O processo de geração do conhecimento e a necessidade futura de competências essenciais em organizações de P\&D. Simpósio de Gestão de Inovação Tecnológica, Curitiba, PR, Brasil, 23.

Magalhães, M. L., \& Borges-Andrade, J. E. (200I). Auto e hetero-avaliação no diagnóstico de necessidades de treinamento. Estudos de Psicologia, 6(I), 33-50.

Mager, R. F. (1977). Análise de objetivos. Porto Alegre: Globo.

Mager, R. F., \& Pipe, P. (1979). Análise de problemas de desempenho (2a ed.). Porto Alegre: Globo.

Matos, F. (I997). A empresa júnior no Brasil e no mundo: o conceito, o funcionamento, a história e as tendências do movimento EJ. São Paulo: Martin Claret.

McGehee, W., \& Thayer, P. W. (I961). Training in business and industry. New York: Wiley.

Meneses, P. P. M., Zerbini, T., \& Abbad, G. S. (2010). Manual de treinamento organizacional. Porto Alegre: Artmed.

Menezes, L. A., Rivera, R. C. P., \& Borges-Andrade, J. E. (I988). Necessidades de treinamento de agricultores e de suas mulheres num projeto integrado de colonização. Cadernos de Difusão de Tecnologia, 5(13), I09-ІІ8.

Moretto, L., Neto, Junkes, P. N., Rosauro, D. Z., \& Benko, F. (2004). Empresa júnior: espaço de aprendizagem. Florianópolis: Gráfica Editora Pallotti.

Ostroff, C., \& Ford, K. (I989). Introducing a levels perspective to training needs assessment. In I. Goldstein (Ed.). Training and career development. San Francisco: Jossey Bass.

Pasquali, L. (I998). Princípios da elaboração de escalas psicológicas. Revista de Psiquiatria Clínica, 25(5), 206-213.

Peres, R. S., Carvalho, A. M. R., \& Hashimoto, F. (2004). Empresa júnior: integrando teorias e práticas em psicologia. Revista Psicologia, Organizações e Trabalho, 4(2), II-30.

Projeto de Lei do Senado Federal n. 437 (2012). Dispõe sobre a regularização das empresas júnior brasileiras. Brasília, DF. Recuperado em ıo dezembro, 20I2, de http://www.senado.gov.br/atividade/materia/detalhes.asp?p_cod_mate=I09380 pdf.

Tannenbaum, S. I., \& Yukl, G. (I992). Training and development in work organizations. Annual Review of Psychology, 43, 399-44I.

Taylor, P., O’Driscoll, M., \& Binning, J. (I998). A new integrated framework for training needs analysis. Human Resource Management Journal, 8(I), 29-50.

Trudeau, K. J., Ainscough, J. L., Trant, M., Starker, J., \& Cousineau, T. M. (20I0). Identifying the educational needs of menopausal women: a feasibility study. Women's Health Issues, 21(2), I45-I52. 